\title{
Mood and recognition memory: A comparison of two procedures
}

\author{
KATHLEEN A. MARSHALL GARCIA and ROBERT C. BECK \\ Wake Forest University, Winston-Salem, North Carolina
}

(Charles L. Richman, Sponsor)

\begin{abstract}
The Bower, Monteiro, and Gilligan (1978) interference-task procedure was compared with a simple learn-test procedure to study mood change and recognition memory for nonsense syllables. Half of the subjects learned one list while happy or sad (induced by the Velton procedure) and were tested $24 \mathrm{~h}$ later while in the same or opposite mood. The other half learned List 1 while happy or sad, learned List $224 \mathrm{~h}$ later while happy or sad, and were tested for recognition of List 1 after another $24 \mathrm{~h}$, while happy or sad. Subjects' mood ratings changed appropriately following either induction procedure, but the only significant memory effect was higher retention among the single-list groups. These results confirm previous failures to find mooddependent-recognition memory effects, but also extend this failure to research using the interference procedure.
\end{abstract}

State-dependent memory (SDM) is an exciting phenomenon because of both its theoretical and its practical applications. It has fit well into associative network theory (Bower, 1981), and Berkowitz (1984) recently extended this theory to account for social contagion and aggression. Sometimes, however, the SDM effect is not found at all or is asymmetrical from one mood to another. Furthermore, the effect has been obtained most readily using free recall testing of affectively biased stimuli in conjunction with a strongly suggestive mood-induction technique (e.g., Bower, 1981), leaving open the strong possibility of experimenter-demand effect. That is, subjects may attend to or report events congruent with the induced mood because they think they should. Most recently, however, Bower and Mayer (1985) were unable to replicate their previously reported results supporting the SDM effect, although they used hypnosis and pleasant versus unpleasant nouns.

With recognition memory tasks, results are frequently negative or ambiguous (Darley, Tinklenberg, Roth, \& Atkinson, 1974; Wicklegren, 1975). One reason for these results may be that, in recognition memory, the external retrieval cues (the previously learned stimuli) may be so powerful that they swamp more subtle SDM effects (Bower, 1981; Eich, 1980). The question we raised was whether a SDM effect could be obtained with a consonantvowel-consonant (CVC) recognition task using the

The present report is based on a thesis in partial fulfillment of the requirements for the Master of Arts Degree in Psychology at Wake Forest University, by the senior author under direction of the junior author. Appreciation is expressed to Charles Richman for his critical comments on the manuscript and to Henry Ellis for detailed information on some procedural details. Communications may be addressed to R. C. Beck, Department of Psychology, Box 7778, Wake Forest University, WinstonSalem, NC 27109. retroactive interference design. This interference task was compared with the single-list procedure.

\section{METHOD}

\section{Subjects and Design}

The subjects were 29 female and 29 male undergraduate students participating for partial course credit in introductory psychology. All potential subjects had been pretested on the Beck Depression Inventory (BDI, Beck, 1967); only those students who scored 10 or below and reported that they were not receiving psychological therapy or taking psychoactive drugs participated. Subjects were randomly assigned to eight experimental conditions, with approximately equal numbers of males and females in each.

Groups 1-4 learned a list of 50 trigrams while elated (E) or depressed (D) and were tested $24 \mathrm{~h}$ later in the same or opposite mood. Those subjects tested while in the same mood were expected to perform better than those tested while in the opposite mood.

Groups 5-8 had an interference task before testing. They learned List 1 while elated or depressed, learned List $224 \mathrm{~h}$ later while elated or depressed, and were tested on List 1 after another $24 \mathrm{~h}$ while elated or depressed. Minimum interference was predicted for conditions DED and EDE, when List 2 was learned in a different state from the test mood. Maximum interference was predicted for conditions DEE and EDD, where the interference list mood was the same as the mood in testing.

\section{Materials}

Elated and depressed moods were induced with the Velton (1968) mood-induction procedure, consisting of 60 happy or sad self-referent statements. A Depression Adjective Checklist (DACL) and an 11-point self-referent mood scale ( $1=$ very depressed and $11=$ very happy) were used to assess mood. The 50-syllable learning lists and a 50-syllable distractor list were each composed of CVC syllables selected from Noble (1961). Association values ranged from 2.0 to 3.25 on the learning list and .4 to 1.65 on the interference and distractor lists. The test list consisted of List 1 syllables randomly mixed with distractor syllables.

\section{Procedure}

Each subject was tested individually. After their moods upon arrival (using the depressed-happy scale) were rated, subjects were given the appropriate mood-induction procedure, and then were given List 1 to study for $4 \mathrm{~min}$. The DACL was then completed, and the mood scale 
was administered a second time. Subjects in Groups 1-4 rated their moods on arrival at the laboratory the next day and completed the appropriate mood induction. They were then given the 100-syllable test list and rated each item on a 5-point scale, "definitely an old item" to "definitely a new item" (Hake \& Rodwan, 1966).

Subjects in Groups 5-8 were given the same procedure except that on the second day they learned List 2 following the appropriate mood induction. They were given the recognition test on the third day. Moods were assessed on each day.

Subjects who received the depression procedure at any session were given a "mood restoration" procedure, 10 of the elation scale items, before leaving. All subjects answered a questionnaire upon completion of the experiment to determine whether there was any demand, but no subject was aware of the purpose of the experiment. All subjects given the depression induction were also contacted by the experimenter during the following week to make sure there were no lasting effects.

\section{RESULTS AND DISCUSSION}

Each of eight groups had a minimum of 6 and a maximum of 8 subjects. The data were analyzed with analyses of variance for unequal Ns.

\section{Mood Assessment}

The Velton procedure was effective for producing the desired moods in each session, as shown by subjects' selfratings of mood. For each single-list group, the mean mood ratings following elation or depression treatments in training and testing were as follows: $\mathrm{DD}=4.0,5.0$; $\mathrm{EE}=8.1,8.0 ; \mathrm{DE}=3.4,8.4 ;$ and $\mathrm{ED}=7.9,5.4$. For the interference groups, which had three inductions, the ratings were: $\mathrm{DED}=5.1,9.0,6.1 ; \mathrm{EDE}=8.1,4.8$, 8.6; $\mathrm{DEE}=5.3,7.8,7.4$; and $\mathrm{EDD}=9.1,5.0,4.7$. Over all the induction conditions, there was no overlap in mean scores for elation and depression conditions. Statistically, ratings changed significantly from initial arrival to post-induction $[F(6,49)=3.28, p<.05]$. As expected, the main effects of mood during training and testing were statistically significant $[\mathrm{F}(1,50)=39.98$, $\mathrm{p}<.01$ for training, and $\mathrm{F}(1,50)=24.15, \mathrm{p}<.01$ for testing]. Scores for the DACL, obtained immediately after learning and after testing, showed the same mood differences [Fs $=48.27$ and 26.29, respectively, $\mathrm{p}<.01]$. In spite of the highly significant differences in mood ratings, however, we may note that on a scale in which 6.0 is neutral, neither the elated nor depressed ratings were very much above or below neutrality.

\section{Recognition Testing}

Memory was measured by using the ratings of items on the old-new dimension to determine four $\mathrm{d}^{\prime}$ values from the ratio of hit rate (HR) to false alarm rate (FAR) at each point (Hake \& Rodwan, 1966). The average of the four $d^{\prime}$ values for each subject was the final score.

Table 1 shows the mean $\mathrm{d}^{\prime}$ scores for each mood condition. The mean scores for the groups are in the predicted directions. In the single-list groups, the mood-shift group means are slightly smaller than the means for the nonshift groups. In the interference task, the means for the high-interference groups were also smaller. However, the
Table 1

Mean Memory Scores (d') for Each of the Eight Experimental Groups

\begin{tabular}{lccccc}
\hline & \multicolumn{4}{c}{ Study Moods } \\
\cline { 2 - 3 } & \multicolumn{2}{c}{ Single List } & & \multicolumn{2}{c}{$\begin{array}{c}\text { Interference } \\
\text { Task }\end{array}$} \\
\cline { 2 - 3 } \cline { 5 - 6 } Test Moods & D & E & & DE & ED \\
\hline Depressed & 1.24 & 1.19 & & .50 & $.46 \mathrm{~h}$ \\
Elated & .78 & 1.14 & & $.42 \mathrm{~h}$ & .60 \\
\hline
\end{tabular}

Note $-D=$ depressed; $E=$ elated $h=$ high interference. In the interference groups, the second letter is the mood during the interference task.

only significant effect was higher recall among the singlelist groups than the interference-list groups $[\mathrm{F}(1,50)=$ $35.51, \mathrm{p}<.01]$. This difference could be due to the interference task or to the longer time interval between learning and testing for the interference groups. Memory scores did not differ as a function of mood during either study or testing ( $p>.10)$, and there was no interaction between $d^{\prime}$ scores and moods $(p>.25)$. Similarly, there was no relation between $\mathrm{d}^{\prime}$ scores and mood change scores $(p>.25)$. We also estimated that doubling the number of subjects would not have produced statistically significant differences.

According to these data, reinstatement of learning mood did not provide an effective retrieval cue for CVC recognition beyond those inherent in the recognition task, for either single-list or interference conditions. The SDM effect thus remains elusive in the recognition-test situation. This conclusion may be tempered by the possibility that the mood changes reported may themselves be artifactual, produced by demand conditions established by the Velton procedure. Following the induction procedure, the subjects may have believed that they should report more extreme happiness or depression than they actually felt. And, as noted, the mood differences reported were not very great, although highly significant statistically. If the mood differences were weak at best, we may not have given the SDM hypothesis a fair test. We avoided demand effects in testing by using emotionally neutral stimuli, but the manipulation checks themselves may have been susceptible to demand. In Bower and Mayer's (1985) report, their manipulation checks also indicated that the subjects were in the appropriate moods following hypnotic induction and suggestion, but the SDM effect was not found. Demand effects may have influenced the manipulation checks, however, and their mood manipulations may not have been as powerful as the researchers believed.

In human research, then, the SDM effect with induced moods may not be so powerful as initial research indicated. Bower and Mayer (1985) suggest that "failure impacts more generally upon any theory that supposes that internal states act as contexts that can become associated with memories of coincident events"' (p. 42). We are left, nevertheless, with what appears to be very good animal data showing that rats can use hunger or thirst very effectively as cues to the presence or absence of reward. Different levels of either state are also predictive (Capaldi 
\& Davidson, 1979). In spite of our mood manipulation checks, then, we may not be dealing with strong enough or different enough moods in the human research to produce the SDM phenomenon reliably. It would not be unreasonable to follow the animal research a little more closely, looking at such states as hunger and thirst as internal context cues for memories.

\section{REFERENCES}

Beck, A. T. (1967). Depression: Causes and treatment. Philadelphia: University of Pennsylvania Press.

BerKowitz, L. (1984). Some effects of thoughts on anti- and prosocial influences of media events: A cognitive-neoassociation analysis. Psychological Bulletin, 95, 410-427.

BOWER, G. H. (1981). Mood and memory. American Psychologist, 36, 129-148.

Bower, G. H., \& MAYER, J. D. (1985). Failure to replicate mooddependent retrieval. Bulletin of the Psychonomic Society, 23, 39-42.

Bower, G. H., Monteiro, K. P., \& Gilligan, S. G. (1978). Emotional mood as a context for learning and recall. Journal of Verbal Learning \& Verbal Behavior, 17, 578-585.
Capaldi, E. D., \& Davidson, T. L. (1979). Control of instrumental activity by deprivation stimuli. Journal of Experimental Psychology: Animal Behavior Processes, 5, 355-367.

Darley, C. F., Tinklenberg, J. R., Roth, W. T., \& AtKinson, R. C. (1974). The nature of storage deficits and state-dependent retrieval under marijuana. Psychopharmacologia (Berlin), 37, 139-149.

EicH, J. E. (1980). The cue-dependent nature of state-dependent retrieval. Memory \& Cognition, 8, 157-173.

Hake, H. W., \& Rodwan, A. S. (1966). Perception and recognition. In J. B. Sidowski (Ed.), Experimental methods and instrumentation in psychology (pp. 331-381). New York: McGraw-Hill.

Noble, C. E. (1961). Measurement of association value (a), rated associations $\left(a^{\prime}\right)$, and scaled meaningfulness $\left(\mathrm{m}^{\prime}\right)$ for $2100 \mathrm{CVC}$ combinations of the English alphabet. Psychological Reports, 8, 487--521.

VeLton, E. (1968). A laboratory task for induction of mood state. Behavioral Research \& Therapy, 6, 473-482.

WICKLEGREN, W. (1975). Alcohol intoxication and memory storage dynamics. Memory \& Cognition, 3, 385-389.

(Manuscript received for publication May 6, 1985.) 